\title{
Useful, Social and Enjoyable: Mobile Phone Adoption by Older People
}

\author{
Mario Conci, Fabio Pianesi, and Massimo Zancanaro \\ FBK-irst, \\ 38123 Trento, Italy \\ \{mconci, pianesi, zancana\} @efbk.eu
}

\begin{abstract}
The paper presents an empirical model of acceptance of mobile phones by elderly people. It is based on an extension of the widely used TAMTechnology Acceptance Model and aims specifically at investigating the relationship among intrinsic and extrinsic motivations to use. The data consists of 740 questionnaires from people over 65 years old. The validated model shows that intrinsic motivations play an important role albeit always mediated by utilitarian motives. Similarly, it emerges a strong influence of the reference social group (children and relatives) in increasing the utilitarian values of the use of mobile phones. These findings suggest that mobile phone usage by elderly might not be, after all, too much different, from a motivational point of view, from that of younger or adult people.
\end{abstract}

Keywords: TAM, mobile phones, elders, intrinsic motivation.

\section{Introduction}

Currently, people aged over 65 represent approximately $13 \%$ of the population, a figure that is expected to increase by 2030 [8]. Although the elderly is still underconsidered in the technology world and seen as a "non technological" person, a substantial amount of studies contend this stereotype [see for example 9]. Indeed, there is no evidence that older people reject technology more than people of other ages; elderly, as anyone else, accept and adopt technology when the latter meets their needs and expectations [49]. Older people can be expected to have a different approach to technology from younger people. Because of sensory, motor, and cognitive changes due to ageing, older people might need more time to learn, be more error-prone, and need more steps to operate the system.

In this paper, we first propose and then investigate on a large group of elderly people living in northern Italy, a model for the acceptance of mobile phones (MP), operationalizing acceptance as the "intention to use" the technology. A major goal of the proposed model is to empirically investigate the motivational structure underlying MP acceptance, by considering both extrinsic (utilitarian) and intrinsic (hedonic) motivations. The results confirm the importance of utilitarian considerations, and particularly of the perceived usefulness, as a driving factor for the intention to use the MP. Yet they also show how intrinsic motivations, and in particular those concerning

T. Gross et al. (Eds.): INTERACT 2009, Part I, LNCS 5726, pp. 63776, 2009.

(C) IFIP International Federation for Information Processing 2009 
self-realization and enjoyment, play an important role, even if the latter is still mediated by utilitarian consideration. Much as for younger people, social pressure is important also for older people, the difference mostly concerns the type of reference group: the children and the relatives for the elders and the peers for young people.

Another important aspect emerging from our study is that the perceived ease of use and the need for support to use MP persist even after years of usage. Compared with the evidence found in the literature showing that those relationships are typical of early stages of technology usage, our findings suggest that older people do not go beyond an initial approach to the MP, but maintain a certain distance with respect to it, even after years of frequent usage.

\section{Related Works}

Despite its enormous growth and social diffusion, the amount of studies in the area of acceptance of mobile phones is relatively small. In recent years, however, researchers have started to focus on the social and psychological aspects of the MP diffusion, and on its impact on people's daily lives and relationships. In consideration of the enormous adoption of the MP among young people, most efforts have been devoted to this age group, with only few studies at present targeting older people. Indeed, younger people have for long been the most active MP users, but in the last few years its usage by people over 60 has also been growing very rapidly. According to a recent survey, in Italy $58.5 \%$ of the people between 65 and 74 and $26.6 \%$ of those above 75 use the MP, with a much higher growth trend in this age group than in others [21].

According to Ling et al. [28] MPs gained so much popularity because they allow people to stay in touch and have easy access to information anywhere and anytime. Among younger people, the motivations towards the use of the MP are social and psychological [10]. Adolescents feel the power of the group, need to be part of a social network, and through the mobile phone they can nurture active networks of social relationships, and prevents the exclusion from the group. With adult users, the initial adoption of the MP seems to rest on safety and job-related reasons rather than social and hedonic ones. The flexible access to information has permitted both an increased productivity, and a timely access to help and support in case of need, improving users' feeling of personal and family security. Safety and security are recognized as most important reasons for MP adoption also among frailer (older and disabled) people, with a positive impact on personal independence [1] and self-image [35]. Aecent work in the tradition of acceptance modelling [45] has highlighted the importance of the distinction between utilitarian and hedonic technologies, and of the related distinction between intrinsic and extrinsic motivations, for the construction of explicit models of technology acceptance. Utilitarian technologies are meant to provide outcomes that go beyond the interaction with the system, usually aiming to provide as much instrumental added value as possible in terms of efficiency and performance. In contrast, hedonic-oriented technologies provide self-fulfilling value to the user; people do not have specific objectives to accomplish, nor do they worry about how and/or when to achieve it. In typical hedonic scenarios e.g. computer games, the focus is not on the instrumental function, but on the interaction with the system, whose value is as higher as greater is the fun experienced by the user during 
the interaction. The distinction between hedonic and utilitarian technologies reflects in the kind of motivations people have when interacting with them. Intrinsic motivations underlie the execution of an activity for the very sake of the execution itself, and not for the attainment of separable consequences; hence, they typically support the usage of hedonic systems. On the other hand, if separable consequences are a target of the activity (hence, with utilitarian systems), extrinsic motivations come into play [45]. It is not straightforward to map the dimensions taken into considerations by the studies mentioned above onto the intrinsic/extrinsic distinction. However, at a first attempt we might suggest that the main motivations for younger people to use the MP are of the extrinsic type: improve and nurture own social network [51]. As to older people, the literature suggests that they prioritize intrinsic motivations (quality of experience, self-image, etc.).

\section{The Model}

The model we propose builds on the Technology Acceptance Model (TAM) [11]. TAM aims to discover the impact of external variables on internal beliefs, attitudes and intentions. It assumes that the actual usage of a technology depends on the individual's intention to use it, which is, in turn, influenced by the perception of the advantages and of the easiness related with technology usage. TAM has been widely used in the literature for investigating technology acceptance, receiving extensive empirical support, as well as extensions to make it more capable to cope with different aspects of technology acceptance. According to Davis et al. [12] we used a modified version of TAM, where the intention to use a system (BI) is directly and significantly influenced both by the Perceived Usefulness of it (PU) and the Perceived Ease of Use it (PEU), without passing through attitude as in the original TAM. This version has been named Parsimonious TAM (pTAM) by Sharp [41]. Below we briefly review studies that modified TAM to account for mobile technology acceptance; none of them targeted a specific age group.

Kwon and Chidambaram' [24] model included: individual characteristics, Perceived Ease of Use, Perceived Usefulness, Enjoyment (an intrinsic motivation), and Social Pressure. Results pointed out a non significant general effect of individual characteristics (gender, income, occupation) on BI to use the mobile phone; age had a significant and positive association with Social Pressure, meaning that older people experience more social pressure in their usage of the MP. The Perceived Ease of Use was also an important factor influencing MP acceptance, and was strongly associated with Enjoyment. Nysveen et al. [34] studied the acceptance of mobile services by extending TAM with Perceived Enjoyment as an antecedent of Attitude and Intention to Use. The results supported a stronger effect of Perceived Usefulness and Perceived Ease of Use for utilitarian than for hedonic services. The situation was reversed for Perceived Enjoyment and Expressiveness. Hong and Tam [19] used Need of Uniqueness and Perceived Enjoyment as antecedents of Perceived Usefulness and Intention to Use in a study about acceptance of mobile data services. Van Biljon and Kotzé [44] proposed a Mobile Phone Technology Adoption Model (MOPTAM), which emphasises the importance of Social Influence and Facilitating Conditions like system service, costs and quality. 
In building our model, we have focused on: a) the motivational structure of MP acceptance (intrinsic vs. extrinsic motivations), b) the influence of the social environment, c) facilitating conditions that may make the usage of the MP easier for the older person and, d) a specific outcome of MP usage consisting of an increased sense of safety. Here follows a review of works that have considered similar constructs in the investigation of the relationship between older people and advanced technologies. According to Ling and Haddon [30], there are several motives associated with the acceptance of the mobile phone, both for young and older people, including accessibility to information, display characteristics, arranging appointments, and safety that is a relevant factor especially for older people. Oksman [35] investigated the use of, and opinions about, the mobile phone by Finnish older people, reporting that many of them wanted to purchase it to increase security and communication, mostly with family member; recently, however, the usage of the mobile phone for communications with friends and acquaintances has increased. Kurniawan [23] reported that older people find the mobile phone more useful if it supports personal communication and provides sense of security, acting as a means of social integration and enhancing autonomy. Phang et al. [37] used TAM to examine the acceptance of an e-government system by older people. They introduced another intrinsic motivator, SelfActualization as antecedent of Perceived Usefulness. They also investigated the effect of declining physiological conditions on Perceived Ease of Use, failing to find any, probably because of adaptive/compensatory behaviours by older people.

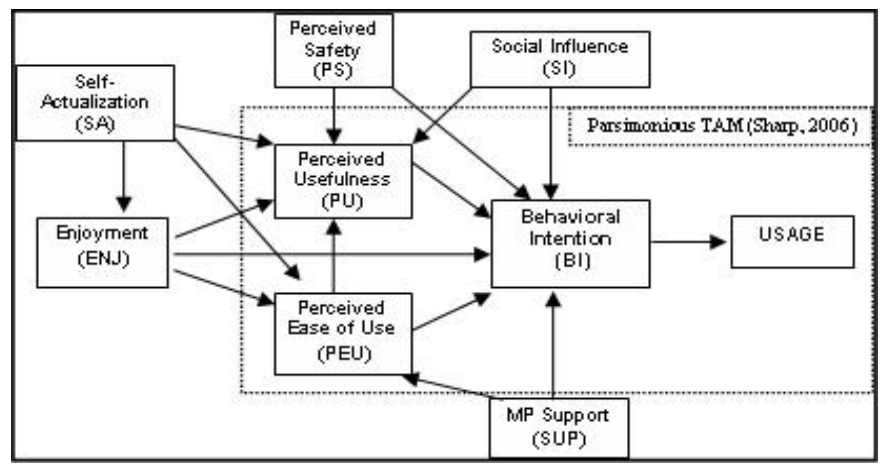

Fig. 1. The research model

The proposed model is displayed in Figure 1. It integrates a pTAM core with Social Influence (SI), Enjoyment (ENJ; an intrinsic motivation), Perceived safety (PS, a relevant outcome), Support to the use of mobile phone (SUP, a facilitating condition) and Self-actualization (SA, another intrinsic motivator). The next subsections discuss the model in greater detail.

\section{1 pTAM Constructs: Behavioural Intention to Use (BI), Perceived Usefulness (PU), and Perceived Ease of Use (PEU)}

Following a common practice, we operationalize the notion of acceptance by means of the construct of Behavioural Intention to use the system (BI) [13]. 
To capture extrinsic motivation we exploit TAM's Perceived Usefulness (PU), defined as the extent to which a person believes that using the given technology will enhance his/her performance [12]. PU picks up utilitarian concerns and the instrumental value attributed to the technology. A significant body of research has shown that PU is a strong determinant of BI [48]. Initial evidence that the PU $\rightarrow \mathrm{BI}$ relationships might hold for elderly was provided by Phang et al. [37], though with a different technology (e-government systems).

Perceived Ease of Use (PEU) is defined as the degree to which a person believes that using a system will be free of effort [12]; in a way, it measures the degree of perceived workload due to the usage of the system: the higher PEU, the lower the perceived workload, and vice versa. Several studies pointed out the influence of PEU on BI and on PU [26], providing support to the idea that an easier technology is felt as more useful, and induces a stronger intention to use the system. It should be noted, however, that there is a certain consensus that the PEU $\rightarrow$ PU relationships holds mainly at the initial stages of technology usage, vanishing when acquaintance with it solidifies. Initial confirmation for the PEU $\rightarrow$ BI link with the MP was provided by Kwon and Chidambaram [24]. Phang et al.[37], in turn, found support for both $\mathrm{PEU} \rightarrow \mathrm{BI}$ and $\mathrm{PEU} \rightarrow \mathrm{PU}$ relations for seniors in their study on e-government services acceptance. In the context of our study, these hypotheses assume that a lower perceived workload when using the mobile phone will make elders keener to use it, and will increase its instrumental value.

H1. Perceived Usefulness has a positive effect on BI.

H2. Perceived Ease of use has a positive effect on PU.

H3. Perceived Ease of use has a positive effect on BI.

\subsection{Social Influence (SI)}

We define Social Influence as the degree to which an individual believes that people who are important to her think she should perform the behaviour in question [48]. We understand it as the feeling of being influenced by relatives and friends (Significant Others) in own usage of the MP. Several works [25, 43, 48] have investigated the possibility that SI affect BI, both directly and indirectly through the mediation of PU. Lee et al. [25] concluded that SI has an unclear effect on BI appearing as a weak predictor in some studies, while having a significant relevance in others. Concerning the mobile phone, SI has been investigated by Teo and Pok [43] as a construct influencing the adoption of a WAP mobile phone among Internet users. They found a positive association between SI and BI, suggesting that people's BI towards adopting a WAP-enable mobile phone is positively related to the influence of their reference groups. Teo and Pok [43] reported that Social Influence has greater effect when the behaviour is new and at the initial stages of adoption. Hypothesising that older people are little experienced with technology in general, they might be expected to follow relatives' opinions in their adoption choices.

H4. Social Influence has a positive effect on PU.

H5. Social Influence has a positive effect on BI. 


\subsection{Enjoyment (ENJ)}

Enjoyment (ENJ), an intrinsic motivation, refers to the extent to which the interaction with the system is perceived to be enjoyable in its own right, apart from any performance consequence that may be anticipated [13].

A growing number of studies suggest that people purchase a mobile phone not just as a business tool but also as a source of enjoyment [24]. Usually ENJ has been studied in relation to technology adoption by young people. We hypothesise that it plays an important role also with older people. Many studies [2, 45] use Enjoyment as an antecedent of PEU and PU, meaning that an enjoyable system is also easier to use and more useful. That is, a high level of Enjoyment increases the instrumental value of the technology [2] and lowers the cognitive burden (the more I enjoy, the more the technology is easy to use). In this work we extend these considerations to the relationship between older people and the MP. Several authors [e.g. 49] found that there is no direct effect of Enjoyment on BI. Chesney [5], however, pointed out the importance for this relation of the system (hedonic vs utilitarian) and of the context where it is used. Following Heerink et al. [17], we assume that with mobile phones (being them at least partially hedonic), enjoyment directly influences the intention to use the mobile phone.

H6. Enjoyment has a positive effect on PU.

H7. Enjoyment has a positive effect on PEU.

H8. Enjoyment has effect on the BI.

\subsection{Perceived Safety (PS)}

Safety is the state of being "safe", the condition of being protected against physical, social, financial, psychological, etc., damages. In this study we consider the possibility that with seniors such a feeling is supported by the usage of the MP, e.g., to face unwelcome situations.

According to Aoki and Downes [3], personal safety is the initial motivation for many young people to obtain a mobile phone from their parents. The few studies about older people and the mobile phone [23] confirm that one of its most important functions is securing a sense of safety. We hypothesize that PS unfolds its effects by directly affecting both PU and BI, so that the more the MP fosters a sense of safety, the more people will find it useful and the more willing to use it they will be.

H9. Perceived Safety has a positive effect on Perceived Usefulness.

H10. Perceived Safety has a positive effect on Behavioural Intention.

\subsection{Mobile Phone Support (SUP)}

Originally, Support referred to the help provided by others to the person in her usage of a computer, in form of resources and knowledge [21]. This definition readily extends to the MP and older people. Getting support is very important to help users to overcome barriers with technology, especially during the early stages of use [48]. Igbaria et al [21], Venkatesh and Morris [48], and Phang et al [37] all showed that Support is positively linked to PEU with several technologies. Richardson et al. [39] 
found similar results for older people's use of internet in non-workplace settings, where participants expressed their explicit need for support from relatives and friends.

We hypothesize that, since older people may be relatively unfamiliar and unsure of mobile phone usage, support by other people such as family members or friends can be a facilitating condition that increases PEU. Following Nysveen et al. [34], we also speculate that receiving support in using the MP increases the intention to use it.

H11. Support has a positive effect on PEU.

H12. Support has a positive effect on BI.

\subsection{Self-Actualization (SA)}

Self-actualization refers to the motivation to achieve everything one is capable of [31]. In Maslow's pyramid of needs, SA sits on the top, meaning that it is one of the most important needs to satisfy, by attempting to develop one's identity, increasing expectations and potentials, and achieving a significant social status. A high level of self-actualization co-occurs with people openness to new experiences and to the learning of new ideas and skills [37]. New technologies, in particular computers, allow people to exchange and gather information, and explore more and more of the world, contributing to actualize the self. Technologies that connect individuals, peers and social groups (as the MP does) hold great potential for learning, personal growth and life enhancement. Finally, the self-actualization tends to be more salient in later adulthood [31].

Following Phang et al [37] we exploit SA as a potential antecedent of PU, hypothesising that a higher SA increases the instrumental value of the mobile phone. Moreover, since SA is connected to intrinsic motivation [4], we theorize that it will also affect Enjoyment in MP usage. Finally, we hypothesise that a highly motivated person who wants to actualize herself by using a MP will experience less effort in using it.

H13. Self-actualization has a positive effect on PU.

H14. Self-actualization has a positive effect on Enjoyment.

H15. Self-actualization has a positive effect on PEU.

\section{The Study}

To explore the model presented above, a survey was conducted by means of mailed questionnaires. Each participant received an envelope containing the questionnaire, a letter of presentation and a second pre-stamped envelope for returning the filled questionnaire. No replying incentive was provided.

Each construct of the research model was measured using standard scales from the literature; when necessary, the scales were adapted to the domain of the study. Subjects were asked to indicate the extent of their agreement/disagreement with each statement of the various scales by means of seven-point Likert scales, anchored to $0=$ "strongly disagree" and 7="strongly agree". Social Influence was measured by the three-item scale used by Hong and Tam [19] to investigate the adoption of mobile 
data services. We measured Perceived Usefulness through Venkatesh and Morris' scale [48, cit. in 26]. Perceived Ease of Use was investigated by means of the scale by Nysveen et al.[34]. Safety was measured by the seven-item scale used by Aoki and Downes [3]. To address Enjoyment we used a three-item scale by Davis et al.[13]. Support was measured by a four-item scale found in [14]. For BI we used Wixom and Todd's [52] scale, while for Self-Actualization, Porter's scale [cit. in 37] was exploited. More details about the scales can be found at the following url: http://www.mediafire.com/?mytwmyrz4cl.

A pilot study was conducted to assess the content of the questionnaire in terms of intelligibility, format and wording. The study involved 24 senior citizens (mean age: 70 years) who were contacted in several Elders Aggregation Centres in Trento, Italy. They compiled the questionnaire together with an experimenter who took notes of doubts and observations. The subjects were then interviewed about their personal experiences with mobile phones and their attitude towards them, reasons for use and not use and anecdotal facts. The results of this pilot study were used to finalize the questionnaire.

\subsection{Participants}

The sample consisted of 2970 people participating in the activities of the Third Age University of Trento. We received 1193 replies, with a response rate of $40 \%$. After discarding incomplete questionnaires, 740 of them were retained for analysis. Among the respondents, $26 \%$ of them were male and $74 \%$ female. The distribution according to age was: (65-69) 33\%, (70-74) 37\%, (75-79) 20\%, ( $\geq 80) 10 \%$. The majority reported to own a mobile phone for longer than one year; $33 \%$ of the subjects declared to use it every day, $40 \%$ several times per week, $24 \%$ several times per month, and $3 \%$ to never use it.

\subsection{Data Analysis}

To analyze the model, PLS-Graph [7] was used. The assessment of the validity of the measurement model (convergent and discriminant validity; reliability) was conducted according to guidelines in [16]. All the relevant criteria were satisfied. For reasons of space, the details of the analysis of the measurement model (including loadings and cross loadings, values of average variance extracted, composite reliability and so on) are not presented here but can be found at http://www.mediafire.com/?mytwmyrz4cl.

The structural model was assessed by computing the significance of the path coefficients through t-testing the results of a bootstrap procedure (200 iterations); the results are reported in Table 1. As can be seen, all the relations are significant except for $\mathrm{PS} \rightarrow \mathrm{BI}$ and ENJ $\rightarrow \mathrm{BI}$. Perceived Usefulness, Perceived Ease of Use, Social Influence, and Support were significantly related to the Behavioural Intention to use the MP, hence supporting $\mathrm{H} 1, \mathrm{H} 3, \mathrm{H} 5$, and $\mathrm{H} 12$; the hypothesised influences of Perceived Safety and Enjoyment on BI were not supported (H8 and H10). Perceived Usefulness was significantly affected by Social Influence, Perceived Safety, SelfActualization, Enjoyment, and Ease to use (H2, H4, H6, H9, and H13). Perceived Ease of Use is significantly influenced by Enjoyment (H7), Support (H11) and SelfActualization (H15). Though, since the relation between SUP and PEU is negative, 
Table 1. Results of Hypothesis Testing* $\mathrm{p}<0.05 ; * * \mathrm{p}<0.01 ; * * * \mathrm{p}<0.001$

\begin{tabular}{|l|l|l|l|}
\hline Hypothesis & Path Coefficient & T-Value & Support \\
\hline H1. PU $\rightarrow$ BI & 0.236 & $3.734^{* * *}$ & Yes \\
\hline H2. PEU $\rightarrow$ PU & 0.111 & $2.923^{* *}$ & Yes \\
\hline H3. PEU $\rightarrow$ BI & 0.225 & $5.798^{* * *}$ & Yes \\
\hline H4. SI $\rightarrow$ PU & 0.196 & $3.904^{* * *}$ & Yes \\
\hline H5. SI $\rightarrow$ BI & 0.155 & $3.014^{* *}$ & Yes \\
\hline H6. ENJ $\rightarrow$ PU & 0.118 & $2.894^{* *}$ & Yes \\
\hline H7. ENJ $\rightarrow$ PEU & 0.448 & $10.329^{* * *}$ & Yes \\
\hline H8. ENJ $\rightarrow$ BI & 0.088 & 2.132 & No \\
\hline H9. PS $\rightarrow$ PU & 0.398 & $8.095^{* * *}$ & Yes \\
\hline H10. PS $\rightarrow$ BI & 0.089 & 1.548 & No \\
\hline H11. SUP $\rightarrow$ PEU & -0.198 & $5.822^{* * *}$ & No \\
\hline H12. SUP $\rightarrow$ BI & 0.191 & $4.180^{* * *}$ & Yes \\
\hline H13. SA $\rightarrow$ PU & 0.146 & $4.318^{* * * *}$ & Yes \\
\hline H14. SA $\rightarrow$ ENJ & 0.541 & $17.820^{* * * *}$ & Yes \\
\hline H15. SA $\rightarrow$ PEU. & 0.166 & $3.534^{* * *}$ & Yes \\
\hline
\end{tabular}

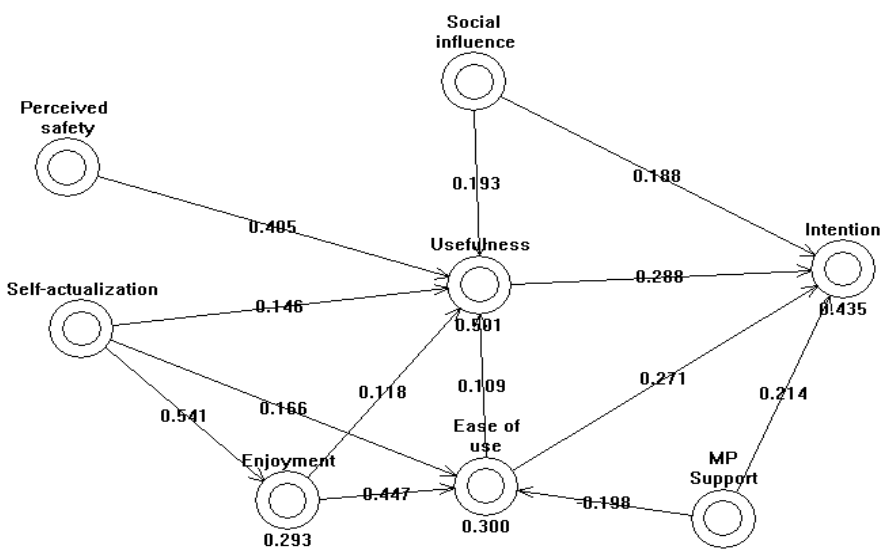

Fig. 2. Final Model

H11 is not supported. Finally, the strong relation between Self-Actualization and Enjoyment supports H14. Once non-significant relationships are dropped, the final model reproduced in Figure 2 is obtained, which reports both the path coefficients and the values of the explained variance, $\mathrm{R}^{2}$.

\subsection{Discussion}

In accordance with the results reported in the literature, feeling safe is a crucial issue for older people; it acts on the intention to use the MP only indirectly, by increasing its utilitarian value. Intrinsic motivations are important factors for older people's adoption of the mobile phone. Enjoyment, which has mostly been studied in relation to young people, has the hypothesised effects of increasing the utilitarian value of the mobile phone, as well as its perceived ease of use. Hence, experiential aspects 
(enjoyment, fun, etc.) are efficacious on mobile phone acceptance in so much as a) they acquire an instrumental value ("I enjoy myself using the mobile phone, hence it is useful, hence I intend to use it"), and b) they contribute to lower the perceived cognitive load. Acceptance of the MP by the elder seem to be built up from utilitarian considerations [3], which are, however, strongly modulated by experiential aspects. Self actualization, the other intrinsic motivator, plays a very similar role to that of Enjoyment: it increases the utilitarian value (PU), lowers the cognitive load and improves the quality of experience (Enjoyment), providing support to Burleson's theory about the synergy among self-actualization, creativity and intrinsic motivations. Thanks to these influences, SA has an important, even if indirect, impact on BI, mediated again by utilitarian considerations.

There is distance between the old person and the mobile phone, though. This is shown by the highly significant relationship between PEU and BI. From the literature we know that in the adoption of technology in organizational settings the perceived ease of use is an important factor at the early stage of adoption, losing its force later on. This is a variety of the novelty effect: technologies that are new, and with a mainly utilitarian value (as the MP, as it turns out), motivate the users to carefully consider the ease of use of the technology when forming their intentions to use it. This effect tends to disappear with practice and with the increase in proficiency in technology usage. Our subjects patterned like early and non-proficient users of utilitarian technologies, in spite of the high frequency of use, and the fact that almost the totality of our subjects has owned a MP for more than 4 years. These findings suggest that even after years of frequent usage, the MP is still perceived as a new and distant technology by older people. This conclusion finds further support in the confirmed effect of SUP on BI. Much as PEU, also the need for support is typically more important at the initial stages of technology adoption. The persistence of its importance for the intention to use the MP (and its inverse relationship to PEU) is coherent with the idea of a stable distance between the MP and older people. Finally, the importance of the pressure from the social environment (in our case, mainly children and other relatives) is confirmed, both as a determinant of extrinsic motivation (PU) and, directly, on the intention to use the MP.

\section{Conclusion}

The contribution of this study is the development and testing of a model addressing a number of dimensions that the literature indicates as potentially relevant to the acceptance of mobile phones by older people. The model builds on pTAM, extending it with constructs that a) complete the motivational structure (Enjoyment and Self Actualization), b) consider the roles of relevant outcomes of the MP usage (Perceived Safety), facilitating condition (Mobile Phone Support) and social environment. As far as we know, this is one of the first attempts aimed at developing and testing a comprehensive model of older people acceptance of the MP.

We believe that the conclusions of this study are quite robust, because of both the statistical method used to analyse the data (PLS) and the size of the sample exploited (740 valid questionnaires). In this connection, we notice that no attempt was made to make the sample representative of the population of reference (e.g., through stratified 
sampling), and, indeed, it would be advisable that our study be replicated by adopting sampling procedures granting representativity. Still, due to the characteristics of the sample, which includes people from urban and rural areas, with different socioeconomical conditions, and an age distribution that is very close to that of the population of reference, we believe our study provides a good and reliable account of the factors underlying MP acceptance by older people.

A key contribution of this study is that it highlights and details the role that intrinsic motivations play in MP acceptance by older people and their interplay with extrinsic ones. Although the basic motivational structure of MP usage turned out to be utilitarian, the fact that extrinsic motivations are strongly modulated by intrinsic one is of the utmost importance for HCI research, suggesting that designers and producers of MPs can leverage on hedonic and self-realization aspects to increase the value of the MP usage and, ultimately, its acceptance. Finally, although it is not possible to draw any straightforward comparisons with other age populations, due to the lack of similar studies for younger or adult people, a comparison with the literature reviewed above suggests that the motivational structure for MP acceptance in older people might share with that of younger and adult ones the emphasis on extrinsic motivations. Nothing can be derived, from those studies, about the way (if any) extrinsic motivations are modulated by intrinsic ones. It might well be that the most interesting differences among age populations is at this level; further studies, based on explicit acceptance models, are needed to explain probable effects.

Another important contribution to the understanding of the factors affecting MP acceptance by older people is the fact that the need for support and the influence of perceived ease of use on intention to use persist even after years of frequent usage. Since these two aspects are typical of early stages of adoption, we have argued that their persistence suggests that older people do not go beyond an initial acquaintance with the MP always maintaining a certain distance with respect to it. According to our model there are at least two ways to improve the overall confidence of older people in the MP: a) contrasting the importance of ease of use by improving long term usability of the MP, and b) given the relationships of Enjoyment and Self Actualization to PEU, leveraging on hedonic and experiential aspect, and on functionalities enhancing self-realization in older people.

\section{References}

1. Abascal, J., Civit, A.: Universal access to mobile telephony as a way to enhance the autonomy of elderly people. In: WUAUC 2001 (2001)

2. Agarwal, R., Karahanna, E.: Time flies when you're having fun: cognitive absorption and beliefs about information technology usage. MIS Quarterly 24, 665-694 (2000)

3. Aoki, K., Downes, E.J.: An analysis of young people's use of and attitudes toward cell phones. Telematics and Informatics 20(4), 349-364 (2003)

4. Burleson, W.: Developing creativity, motivation, and self-actualization with learning systems. Int. Journal Human-Computer Studies 63(4-5), 436-451 (2005)

5. Chesney, T.: An acceptance model for useful and fun information systems. Human Technology 2(2), 225-235 (2006) 
6. Chin, W.W.: The partial Least Square Approach to Structural Equation Modelling. In: Marcoulides, G.A. (ed.) Modern Methods for Business Research. Lawrence Erlbaum Associates, Mahwah (1998)

7. Chin, W.W., Frye, T.: PLS-Graph, Version 3.00 (Build 1026). University of Houston (2001)

8. Czaja, S.J., Hiltz, S.R.: Digital aids for an aging society. Communications of the ACM 48, $10(2005)$

9. Czaja, S.J., Lee, C.C.: The internet and older adults: design challenges and opportunities. In: Charness, N., Park, D.C., Sabel, B.A. (eds.) Communication, technology and aging: opportunities and challenges for the future. Springer, New York (2001)

10. Davie, R., Panting, C., Charlton, T.: Mobile phone ownership and usage among preadolescents. Telematics and Informatics 21, 359-373 (2004)

11. Davis, F.D.: Perceived usefulness, perceived ease of use and user acceptance of information technology. MIS Quarterly 13(3), 319-340 (1989)

12. Davis, F.D., Bagozzi, R.P., Warshaw, P.R.: User acceptance of computer technology: a comparison of two theoretical models. Management Science 35, 982-1002 (1989)

13. Davis, F.D., Bagozzi, R.P., Warshaw, P.R.: Extrinsic and intrinsic motivation to use computers in the workplace. Journal of Applied Social Psychology 22, 1111-1132 (1992)

14. Eisma, R., Dickinson, E.A., Goodman, J., Syme, A., Tiwari, L., Newell, A.F.: Early user involvement in the development of information technology-related products for older people. Univ. Access Inf. Soc. 3, 131-140 (2004)

15. Fornell, C., Larcker, D.F.: Evaluating Structural Equation Models with Unobservable Variables and Measurement Error. Journal of Marketing Research 18, 39-50 (1981)

16. Gefen, D., Straub, D.: A practical Guide to Factorial Validity Using PLS-Graph: Tutorial and annotated Example. Communications of the Association for Information Systems 16, 91-109 (2005)

17. Heerink, M., Kröse, B., Wielinga, B., Evers, V.: Enjoyment, Intention to Use and Actual Use of a Conversational Robot by Elderly People. In: HRI 2008 (2008)

18. Höflich, J.R., Rössler, P.: Mobile schriftliche Kommunikation oder: E-Mail für das Handy. Medien \& Kommunikationswissenschaft 49, 437-461 (2001)

19. Hong, S.J., Tam, K.Y.: Understanding the Adoption of Multi-purpose Information Appliances: The Case of Mobile Data Services. Inf. Systems Research 17(2), 162-179 (2006)

20. Igbaria, M.: End-User computing effectiveness: A structural equation model. Omega 18(6), 637-652 (1990)

21. Igbaria, M., Zinatelli, N., Cragg, P., Cavaye, A.L.M.: Personal computing acceptance factors in small firms: a structural equation model. MIS Quarterly 21(3), 279-301 (1997)

22. Knowledge for business,

http: / / www. key4biz.it/News/2008/05/06/Tecnologie/ cellulare_Istat_televisione_bambini.html

23. Kurniawan, S.: Mobile phone design for older persons. Interactions 24(4), 24-25 (2007)

24. Kwon, H.S., Chidambaram, L.: A test of the Technology Acceptance Model: the case of cellular telephone adoption. In: Proc. of the $33^{\text {rd }}$ Hawaii Int. Conf. on System Sciences (2000)

25. Lee, Y., Lee, J., Lee, Z.: The effect of self identity and social identity on technology acceptance. In: $22^{\text {nd }}$ Int. Conference on Information Systems (2001)

26. Legris, P., Ingham, I., Collerette, P.: Why do people use information technology? A critical review of the technology acceptance model. Inf. Management 40(3), 191-204 (2003) 
27. Lin, C.A.: Looking back: the contribution of Blumer and Katz's uses of mass communication research. Journal of Broadcasting and Electronic Media 40, 574-582 (1996)

28. Ling, C., Hwang, W., Salvendy, G.: Diversified users' satisfaction with advanced mobile phone features. Univ. Access Information Society 5, 239-249 (2006)

29. Ling, R.: It is 'In.' It doesn't matter if you need it or not, just that you have it: Fashion and the Domestication of the Mobile Telephone among teens in Norway. Telenor R\&D, Norway (2001)

30. Ling, R., Haddon, L.: Mobile telephony, mobility and the coordination of everyday life. In: Katz, E. (ed.) Machines that Become Us. The Social Context of Personal Communication Technology. Transaction Publishers, New Brunswick (2002)

31. Maslow, A.H.: Motivation and Personality, 2nd edn. Harper \& Row, New York (1970)

32. Mayhorn, C.B., Lanzolla, V.R., Wogalter, M.S., Watson, A.M.: Personal digital assistants as medication reminding tools: exploring age differences in usability. Gerontechnology 4(3), 128-140 (2005)

33. Nelson, B.D., Carey, A., Friedman, M.: Cell Phone Use by Adults With Intellectual Disabilities. Intellectual and Developmental Disabilities 45(1), 1-9 (2007)

34. Nysveen, H., Pedersen, P.E., Thorbjørnsen, H.: Intention to use Mobile Services: Antecedents and Cross-Service Comparisons. Journal of the Academy of Marketing Science 33(3), 330-346 (2005)

35. Oksman, V.: Young People and Seniors in Finnish 'Mobile Information Society'. Journal of Interactive Media in Education 2 (2006)

36. Pedersen, P.E., Ling, R.: Modifying Adoption Research for Mobile Internet Service Adoption: Cross-Disciplinary Interactions. In: Proc. HICSS 2003 (2003)

37. Phang, C.W., Sutanto, J., Kankanhalli, A., Li, Y., Tan, B.C.Y., Teo, H.H.: Senior Citizens' Acceptance of Information Systems: A Study in the Context of e-Government Services. IEEE Transactions on Engineering Management 53(4), 555-569 (2006)

38. Quadrello, T., Hurme, H., Menzinger, J., Smith, P.K., Veisson, M., Vidal, S., Westerback, S.: Grandparents use of new communication technologies in a European perspective. European Journal of Ageing 2, 200-207 (2005)

39. Richardson, M., Weaver, J.K., Zorn, T.E.: Getting on: older New Zelanders'perceptions of computing. New Media Society 7(2), 219-245 (2005)

40. Selwyn, N., Gorard, S., Furlong, J., Madden, L.: Older adults' use of information and communications technology in everyday life. Ageing \& Society 23, 561-582 (2003)

41. Sharp, J.H.: Development, extension and application: a review of the technology acceptance model. In: Proc. ISECON 2006 (2006)

42. Skog, B.: Mobiles and the Norwegian Teen: Identity, Gender and Class. In: Katz, J.E., Aakhus, M.A. (eds.) Perpetual Contact, Mobile Communication, Private Talk, Public Performance. Cambridge University Press, Cambridge (2002)

43. Teo, T.S.H., Pok, S.H.: Adoption of WAP-Enabled Mobile Phones among Internet Users. Omega 31, 483-498 (2003)

44. Van Biljon, J., Kotzé, P.: Modelling the Factors that influence Mobile Phone Adoption. In: Proc. Annual research conference of the South African institute of computer scientists and information technologists on IT research in developing countries (2007)

45. Van der Heijden, H.: User acceptance of hedonic information systems. MIS Quart. 28(4), 695-704 (2004)

46. Venkatesh, V.: Determinants of perceived ease of use: integrating control, intrinsic motivation, and emotion into the technology acceptance model. Information System Research 11(4), 342-365 (2000) 
47. Venkatesh, V., Davis, F.D.: A model of the antecedents of perceived ease of use: development and test. Decision Sciences 27, 451-481 (1996)

48. Venkatesh, V., Morris, M.G.: Why don't men ever stop to ask for directions? Gender, social influence and their role in technology acceptance and usage behaviour. MIS Quarterly 24(1), 115-139 (2000)

49. Venkatesh, V., Morris, M.G., Davis, G.B., Davis, F.D.: User acceptance of information technology: toward a unified view. MIS Quarterly 27, 3 (2003)

50. Wei, R.: Motivations for using the mobile phone for mass communications and entertainment. Telematics and Informatics 25, 36-46 (2008)

51. Wilska, T.A.: Mobile phone use as part of young people's consumption styles. Journal of Consumer Policy 26, 441-463 (2003)

52. Wixom, B.H., Todd, P.A.: A Theoretical Integration of User Satisfaction and Technology Acceptance. Information Systems Research 16(1), 85-102 (2005)

53. Zimmer, Z., Chappell, N.L.: Receptivity to new technology among older adults. Disability and Rehabilitation 21(5/6), 222-230 (1999) 